\title{
PERIODISMO LENTO (SLOW JOURNALISM) EN LA ERA DE LA INMEDIATEZ. EXPERIENCIAS EN IBEROAMÉRICA
}

\author{
Slow journalism in the immediacy era. \\ Experiences in Ibero-America
}

Gloria Rosique-Cedillo y Alejandro Barranquero-Carretero

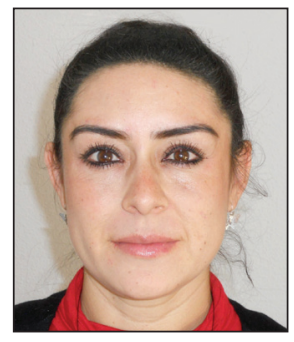

Gloria Rosique-Cedillo es doctora con mención europea en periodismo y profesora en el Departamento de Periodismo y Comunicación Audiovisual en la Universidad Carlos III de Madrid. Sus principales líneas de investigación son participación y fiscalización ciudadana de los medios, televisión y contenidos, documental audiovisual y sistemas comparados de educación universitarios. http://orcid.org/0000-0001-6979-7554

grosique@hum.uc3m.es

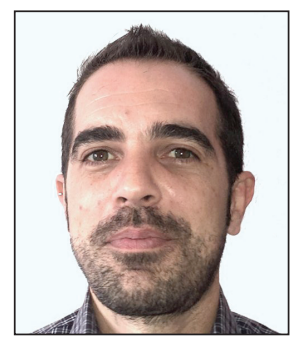

Alejandro Barranquero-Carretero es doctor en periodismo y profesor en el Departamento de Periodismo y Comunicación Audiovisual en la Universidad Carlos III de Madrid. Sus líneas de investigación se centran en la comunicación para el desarrollo y para el cambio social, estrategias informativas de ONGs y movimientos sociales, comunicación/educación y sociología de la cultura. http//orcid.org/0000-0002-9264-9389

abarranq@hum.uc3m.es

Universidad Carlos III de Madrid, Departamento de Periodismo y Comunicación Audiovisual Facultad de Humanidades, Comunicación y Documentación Calle Madrid, 126. 28903 Getafe, Madrid, España

\section{Resumen}

El periodismo lento es aquel que emerge como reacción a la tendencia dominante a la inmediatez y la primicia y que invita a repensar los tiempos necesarios para producir y consumir una información rigurosa, creativa y de calidad. Tras describir los fundamentos históricos y conceptuales de este fenómeno en alza, se analizan cinco experiencias del ámbito iberoamericano: Jot Down, FronteraD, La silla vacía, Anfibia y El puercoespín. Nacidos a finales de 2000, estos nativos digitales ejemplifican la revitalización de un periodismo de largo formato y cuidada factura dirigido a clubes de lectores especializados que demandan una recepción periodística más pausada.

\section{Palabras clave}

Periodismo lento; Movimiento slow; Periodismo narrativo; Periodismo de investigación; Nuevo periodismo; Periodismo alternativo; Periodismo especializado; Medios digitales; Prensa; Revistas; Inmediatez; Calidad; Internet; Jot down; FronteraD; La silla vacía; El puercoespín; Anfibia.

\footnotetext{
Abstract

Slow journalism is a reaction to the dominant journalistic trend to immediacy and scoop and invites us to reflect on the time required to produce and consume rigorous, creative and quality information. After describing the historical and conceptual grounds of this emerging trend, we analyse four paradigmatic experiences in the Ibero-American context: Jot down, FronteraD, La silla vacía, Anfibia and El puercoespín. Born in the late 2000s, these digital natives exemplify the revival of long-form and carefully executed journalism aimed at specialized clubs of readers who demand a more thoughtful approach to journalism.
}

\section{Keywords}

Slow journalism; Slow movement; Narrative journalism; Investigative journalism; New journalism; Alternative journalism; Specialized journalism; Online Media; Magazines; Immediacy; Quality; Internet; Jot down; FronteraD; La silla vacía; El puercoespín; Anfibia. 
Rosique-Cedillo, Gloria; Barranquero-Carretero, Alejandro (2015). "Periodismo lento (slow journalism) en la era de la inmediatez. Experiencias en Iberoamérica”. El profesional de la información, v. 24, n. 4, pp. 451-462.

http://dx.doi.org/10.3145/epi.2015.jul.12

Lectores sin prisa, advertidos de que toda opinión justa es larga de expresar

Ortega y Gasset, El espectador, 1916

\section{El culto a la velocidad}

La velocidad es uno de los signos más definitorios de las sociedades contemporáneas, en las que existe una tendencia imparable a la compresión del tiempo y el espacio (Harvey, 1998) y en las que la política, la economía e incluso la cultura avanzan a una celeridad que el ser humano es incapaz de asimilar. En este contexto algunas voces invitan a estudiar cómo la velocidad -y su ciencia, la "dromología"- pueden llegar a conducirnos al "accidente global" (Virilio, 2012), la "desmaterialización" del mundo (Baudrillard, 1984) y una realidad "pobre en interrupciones, en entes y entretiempos en la que la hiperactividad no deja espacio para la atención o el don de la escucha, cualidades necesarias para fomentar el pensamiento crítico, la creatividad y los vínculos sociales" (Han, 2012, pp. 55-56).

Pero la velocidad no es un fenómeno nuevo ni debe asociarse en exclusiva a la rapidez a la que hoy advocan las nuevas tecnologías. De hecho la aceleración es una de las características de la modernidad, que introdujo la noción ilustrada del progreso o la idea de que el futuro puede ser dirigido y precipitado mediante el uso de la razón humana (Koselleck, 2004).

A partir del siglo XIX el capitalismo industrial forja una nueva relación entre aceleración, productividad y crecimiento, en la que los modelos de producción en cadena intentan maximizar el beneficio mediante el control estricto del tiempo necesario para cumplir cada tarea (Rosa, 2013). Estos patrones se consolidan en la era de las tecnologías de la información, en la que la producción industrial ha sido progresivamente sustituida por el acceso a productos personalizados sometidos al ritmo cambiante del gusto y la moda (Rocamora, 2013) y en torno al mandato capitalista de convertir el tiempo en dinero y abolir toda pérdida de tiempo (Rabhi, 2013, p. 18).

En el ámbito de la comunicación, la búsqueda de tecnologías para superar las limitaciones espacio-temporales ha sido una constante a lo largo de la historia, con hitos como la invención del telégrafo en el siglo XIX, o la extensión de la radio y la televisión en el XX. Estas mutaciones facilitaron el seguimiento al minuto de la actividad noticiosa, pero el periodismo se fue asimilando cada vez más al "valor-noticia" de la inmediatez y a la narración descontextualizada del presente más cercano. Esta tendencia alcanzó su cénit con la invención del directo televisivo en la década de los 50 , con la que los medios aceleraron su carrera imparable por la primicia, al tiempo que la programación tomaba la forma de extensos ciclos noticiosos de 24 horas y 7 días a la semana (Cushion; Lewis, 2010). Al finalizar el segundo milenio, los nuevos soportes digitales -internet, telefonía móvil, etc.- han reforzado aún más la posibilidad de acceder a las noticias de manera ubicua e instantánea y hoy las agendas informativas están marcadas por el devenir noticioso de redes sociales como Twitter que se caracterizan por un flujo informativo imparable, veloz y de formato breve (Revers, 2014).

\section{La velocidad en sí misma no es negativa. El problema estriba en el culto a la velo- cidad}

La actualización continua es uno de los rasgos más valorados en la información online por parte de las audiencias (Chung; Yoo, 2008), pero en la carrera de los medios por ser los primeros, algunas noticias se publican sin haber completado un proceso riguroso de verificación y contraste de hechos o fuentes (Juntunen, 2010; Spence; Quinn, 2008). Nos encontramos en una época de sobreabundancia informativa en la que la "economía de la atención" está marcando las estrategias empresariales de muchos medios, que intentan conseguir una "modulación eficaz entre el caudal informativo y la capacidad de absorción de las audiencias" (Díaz-Nosty, 2013, p. 137). La obsesión por la rapidez no parece dejar espacio para la duda, la reflexión y el análisis contextualizado y construye un periodismo de fácil consumo orientado a gente que no dispone de tiempo para concentrarse y saborear la información hasta "integrarla en un marco que le dé sentido" (Morin, 2011, p. 141).

Cuando la velocidad se impone como horizonte último del periodismo, se acaban descuidando valores deontológicos fundamentales como el de crear información veraz, plural y contrastada. Pierre Bourdieu (1997, p. 29) denunció hace años que los índices de audiencia imponían tal presión que los periodistas tendían a someter su pensamiento y declaraciones a una especie de censura temporal que terminaba por aportar opiniones banales y consensuadas por la mayoría. Por su parte Rosenberg y Feldman destacan que con la extensión de internet, la tiranía del tiempo real se traduce en una merma del tiempo de reflexión para procesar informaciones complejas y en una multiplicación constante de los errores periodísticos: "internet ha transformado no sólo los medios, sino también al periodista. La extrema velocidad de internet y del flujo de noticias de 24 horas -así como la imprudente e irresponsable voluntad de cubrirlo todo, verdadero o no, confirmado o no- altera inevitablemente el comportamiento de aquellos que lo cubren, hasta desarrollar una mentalidad de asedio constante" (Rosenberg; Feldman, 2010, p. 30). 


\section{La reacción slow}

Desde mediados de 1980 se vienen gestando movimientos que invitan a repensar la temporalidad y a desacelerar los ritmos vertiginosos de la vida moderna. Su objetivo es "reconectar al ser humano con su entorno más cercano y ajustar qué celeridad conviene a cada contexto" (Honoré, 2012, p. 23), evitando patologías relacionadas con entornos en exceso versátiles y "líquidos" (Bauman, 2006): ansiedad, estrés, déficit de atención, hiperactividad, etc. El más representativo de estos movimientos es el slow, que se gesta en 1986 durante unas protestas contra la apertura de un restaurante de comida rápida en Roma y que durante la década de los 90 se extiende a ámbitos tan diversos como el urbanismo (slow cities), la educación (slow schooling) o el trabajo (slow working) (Honoré, 2012; 2013).

Desde finales de la década de 2000 el desafío slow también ha llegado al campo de la teoría y la práctica de la comunicación, con propuestas que emergen paradójicamente de un universo digital cuestionado por su tendencia a la sobreabundancia y la desinformación. El movimiento arranca con la publicación de dos manifiestos online que invitan a moderar los ritmos de producción y consumo informativos:

- Not so fast: A manifesto for slow communication (Freeman, 2009a);

- The slow media manifesto (2010), de los blogueros alemanes Sabria David, Jörg Blumtritt y Benedikt Köhler. http://en.slow-media.net/manifesto

En paralelo a la divulgación de estos documentos podemos distinguir tres áreas de investigación en torno a la idea de una comunicación lenta.

En primer lugar un conjunto de trabajos invitan a llevar a cabo estrategias de "dieta informacional" (Andrejevic, 2013; Brabazon, 2013; Freeman, 2009b; Sieberg, 2011; Whitworth, 2009) frente a los nuevos entornos multitarea y el "maximalismo digital" o la convicción de que la conectividad permanente es siempre positiva (Serrano-Puche, 2014). Estos análisis plantean la necesidad de profundizar en una alfabetización mediática que conlleve momentos de desaceleración y desconexión digital a fin de conseguir un consumo más equilibrado y liberar tiempo para la comunicación interpersonal y de proximidad.

En segundo lugar otra línea de trabajos incita a reconsiderar el carácter material y ecológico de las tecnologías y los medios frente a las perspectivas teóricas que han dominado el estudio de la comunicación, más centradas en su carácter simbólico e inmaterial: retórica, semiótica, fenomenología, cibernética, sociopsicología, etc. (Craig, 1999). Las tecnologías y los medios son factores contaminantes de primer orden, por lo que resulta necesario desacelerar los ritmos de producción y desgaste de materia y energía, así como limitar los mensajes antiecológicos a los que abocan las industrias culturales y la publicidad comercial (Maxwell; Raundalen; Vestberg, 2014; Williams, 2011).

Por último, existe una línea incipiente de investigación sobre las prácticas periodísticas lentas que han surgido en los últimos años como reacción al periodismo automático y superficial y entre las que cabe destacar la reactivación del periodismo narrativo y de largo formato (Greenberg, 2012; Gess, 2012; Le-Masurier, 2015; Rauch, 2011). Muchos de estos proyectos entroncan con los valores que promueven los colectivos slow entre los que destacan (BarranqueroCarretero, 2013):

- revalorización de la calidad periodística frente a la cantidad;

- promoción de la diversidad cultural y las relaciones de proximidad frente a la universalidad;

- apuesta por la reflexión en profundidad contra la inmediatez y la superficialidad;

- creatividad frente a la tendencia a la estandarización de muchas noticias.

El periodismo slow emerge como reacción a la novedad, brevedad e instantaneidad, e invita a repensar los tiempos necesarios para producir y consumir una información rigurosa, creativa y de calidad

\section{Algunas pistas para pensar la lentitud periodística}

Resulta complejo definir el periodismo slow, puesto que los trabajos académicos publicados hasta la fecha no aportan una definición exhaustiva de qué implica la lentitud en las etapas de un proceso comunicacional: búsqueda de información, concepción de una noticia, distribución informativa y consumo por parte de la ciudadanía. En cualquier caso, y ampliando estos debates, se define aquí el periodismo slow como el que emerge como reacción a la tendencia periodística dominante a la novedad, la brevedad y la instantaneidad y que invita a repensar los tiempos necesarios para producir y consumir una información rigurosa, creativa y de calidad. El periodismo lento evita la competición extrema por la primicia y pone en entredicho géneros y formatos (como la propia noticia, la prensa gratuita, el periodismo en redes sociales, etc.), que de alguna manera están abocados a una concisión extrema, con lo que esto conlleva de simplificación, descontextualización y fragmentación de realidades más complejas.

Forman parte del periodismo lento aquellas expresiones que:

a) desafían el ciclo 24 horas/7 días a la semana (24/7) y rescatan temporalidades más pausadas como la semana, el mes o el trimestre;

b) no toman en cuenta la extensión de la información periodística, sino que, en la búsqueda de la calidad y el rigor, reivindican el periodismo de largo formato (longform journalism) y géneros como el reportaje en profundidad, el ensayo, la crónica o la entrevista;

c) censuran la lógica de la novedad, lo inmediato o lo desacostumbrado como principales valores-noticia y, en su lugar, atienden a las necesidades de los ciudadanos como criterio último para definir lo noticioso. 
El periodismo lento no sería entonces un fenómeno nuevo, dado que estas fórmulas periodísticas han convivido a lo largo de la historia con las derivadas de la implantación progresiva de técnicas aceleradoras del proceso informativo como las antes descritas (telégrafo, internet, etc.). Cabe citar dos corrientes periodísticas que tradicionalmente han apostado por un periodismo de calidad y de largo formato, al margen del seguimiento estricto de la actualidad más inmediata.

El flujo informativo de 24 horas / 7 días a la semana genera una mentalidad de asedio constante

La primera es la ya larga tradición de periodismo de investigación en la que los profesionales no se limitan a describir la realidad sino que promueven la interpretación de sus causas y una elaboración pausada de las historias, incidiendo a la vez en la actividad fiscalizadora de los medios con respecto al resto de poderes. Sus orígenes se sitúan en prácticas como las de los muckrakers estadounidenses desde finales del siglo XIX (Lincoln Steffens, Jacob Riis, Ida M. Tarbell, Upton Sinclair, etc.), que orientaron sus largos escritos a movilizar a los ciudadanos frente a la corrupción política o las desigualdades sociales, y cuyo legado abanderaron años más tarde periodistas de la talla de Ryszard Kapuściński, Carl Bernstein, Bob Woodward, Günter Wallraff o Seymour Hersh (Herrscher, 2012).

En segundo lugar existe una extensa línea de trabajos que combinan el periodismo con técnicas procedentes de la literatura y que se ha conocido habitualmente como periodismo narrativo. Dentro de esta tradición destacan los escritos del denominado "nuevo periodismo" (new journalism) estadounidense de las décadas de 1960 y 1970 (Tom Wolfe, Norman Mailer, Gay Talese, Truman Capote, etc.), que apostó por la ruptura del canon objetivista en favor de una mayor implicación personal del informador en la historia. Algunas de las revistas que impulsaron el mejor periodismo de investigación del siglo XX también publicaron las extensas crónicas y reportajes de estos autores: Atlantic monthly, Harper's, Esquire, The New Yorker, Rolling stone, etc. (LeMasurier, 2015).

En España la denominada Edad de oro del periodismo español, desde finales del siglo XIX hasta la Guerra civil, estuvo marcada por distintas generaciones de escritores $(98,14$, 27) que combinaron periodismo, literatura e investigación en una rica tradición de articulismo político o cultural, y entre los que podemos destacar autores como Mariano De Cavia, Azorín, Julio Camba o Manuel Chaves Nogales, con interesantes precedentes desde principios del XIX: Mariano José De Larra, Mesonero Romanos, José María Blanco White, etc.

Algo similar se dio en el periodismo latinoamericano a partir del boom literario de las décadas de 1960 y 1970, que se fraguó en buena medida en las conocidas crónicas periodísticas de Gabriel García Márquez o Mario Vargas Llosa y en las que algunos críticos sitúan una variante del new journalism, del que también Rodolfo Walsh es uno de los precursores destacados. Por otro lado y ya en tiempos recientes, varios estudios confirman la vitalidad de la denominada "nueva crónica latinoamericana", heredera de los movimientos anteriores y en la que destaca una nutrida lista de autores como los argentinos Tomás Eloy Martínez, Leila Guerriero o Martín Caparrós o los mexicanos Elena Poniatowska, Lydia Camacho, Juan Villoro y Carlos Monsiváis (Angulo, 2013; Carrión, 2012)

Durante las dos últimas décadas del siglo XX, la nueva crónica latinoamericana se ha forjado en las redacciones de muchos periódicos de la región, al tiempo que en España las innovaciones se ensayaban fundamentalmente en el ámbito de la columna y los géneros de opinión (Rodríguez-Rodríguez; Albalad-Aiguabella, 2012, p. 293).

Esta tendencia avanza en paralelo a la revitalización del periodismo narrativo en todo el mundo (Neveu, 2014; Herrscher, 2012) y al surgimiento en España y en Latinoamérica de un sinfín de cuidadas revistas inspiradas en el modelo editorial anglosajón (Atlantic monthly, The New Yorker, etc.), y entre las que cabría destacar, por su carácter pionero:
- Lateral (Barcelona, 1994-2006);
- El malpensante (Colombia, 1996);
- Letras libres (México, 1999);
- Gatopardo (Colombia, 2001);
- Etiqueta negra (Perú, 2002).

Este género ha tenido una importante repercusión tanto en formato digital como en papel, puesto que muchos cronistas y periodistas de investigación se han embarcado en la puesta en marcha de editoriales y revistas especializadas que recuperan las historias detalladas y rigurosas, sin que haya límite para la extensión de las piezas (Rodríguez-Rodríguez; Albalad-Aiguabella, 2012).

\section{Los antecedentes de los proyectos slow se sitúan en el periodismo narrativo y de investigación}

\section{Periodismo lento en el espacio digital iberoamericano}

Resulta complejo delimitar las publicaciones lentas más significativas del actual panorama iberoamericano por cuanto existe una extensa variedad de iniciativas que cumplen con las características que hemos definido. Este trabajo ha optado por plantear una recopilación extensa de proyectos destacados a un lado y otro del Atlántico (tabla 1) y describir la actividad de un conjunto de publicaciones de referencia que cumplen con los siguientes criterios:

a) son nativas digitales (digital natives), aunque posteriormente hayan iniciado estrategias de publicación en formato papel, creadas a finales de la década de 2000;

b) cuentan con una periodicidad no diaria y marcan su propia agenda informativa con independencia de los grandes medios, priorizando los géneros lentos -crónica, reportaje, etc.- y formas de periodismo de investigación y/o narrativo; 
c) la extensión media de sus piezas es superior a las 2.000 palabras;

d) se autocalifican como "periodismo lento" o promueven una llamada al periodismo de calidad frente al predominio de la cultura rápida.

A tal efecto, además de una extensa tarea de revisión documental de los fondos de estas publicaciones, se partió de un conjunto de entrevistas estructuradas a sus responsables directos, sin cuya ayuda desinteresada no habría sido posible la consecución de este trabajo. En concreto se habló con:

- Ricardo Jonás, fundador y subdirector de Jot down;

- Federico Bianchini, editor de la revista Anfibia;

- Alfonso Armada, director de FronteraD, a partir de la mediación de Carlos García Santa Cecilia, implicado en el proyecto desde sus inicios.

Sus testimonios se combinan con otras fuentes secundarias como declaraciones en prensa y bibliografía especializada.

\section{Jot down \\ http://www.jotdown.es}

En España uno de los ejemplos recientes es la revista cultural Jot down cultural magazine, nacida en formato digital en mayo de 2011. Creada por un grupo de amigos no relacionados con el periodismo -algo excepcional en este tipo de iniciativas-, el proyecto partió de una inversión inicial de sus dos fundadores, Ángel Fernández y Ricardo Jonás, además de otros cuatro colaboradores. Jot down nació sin redacción física y contando con la colaboración desinteresada de escritores de renombre y blogueros menos conocidos. Durante el primer año nadie recibió sueldo ni gratificación económica, ni existió ningún tipo de financiación externa a fin de garantizar la independencia de los contenidos ${ }^{1}$. En 2012 los fundadores consiguieron acometer uno de los objetivos iniciales del proyecto: editar una publicación trimestral en formato papel, que es hoy su principal forma de financiación, además de un pequeño montante derivado de patrocinios y publicidad -muy cuidada y seleccionada a fin de garantizar la independencia-, y un store para suscripción y venta directa de revistas y libros a cargo de la editorial Jot Down Books. En contenidos Jot down no se guía por la agenda informativa diaria, sino que promueve un periodismo atemporal con predominio de temas culturales. La publicación se ha autodefinido como un "himno al fuego lento" (Koch, 2012), dirigida a un target que se siente identificado con un ideal de lectura reposada y atenta
Tabla 1

\begin{tabular}{|c|c|c|}
\hline \multicolumn{3}{|c|}{ España } \\
\hline Jot down & Papel y digital & http://www.jotdown.es \\
\hline La marea & Papel & http://www.lamarea.com \\
\hline Yorokobu & Papel y digital & http://www.yorokobu.es \\
\hline Periodismo humano & Digital & http://www.periodismohumano.com \\
\hline Frontera D & Digital & http://www.fronterad.com \\
\hline Libero & Papel & http://www.revistalibero.com \\
\hline Vía 52 & Digital & http://www.via52.com \\
\hline Diagonal & Papel y digital & http://www.diagonalperiodico.net \\
\hline Materia & Digital & http://www.esmateria.com \\
\hline Cuadernos del basket & Papel & http://www.cuadernosdebasket.com \\
\hline Tinta libre & Papel & http://www.infolibre.es \\
\hline Alternativas económicas & Papel y digital & http://www.alternativaseconomicas.coop \\
\hline Números rojos & Papel & http://www.revistanumerosrojos.com \\
\hline Altaïr magazine & Digital & http://www.altairmagazine.com \\
\hline Panenka & Papel y digital & http://www.panenka.org \\
\hline Ballena blanca & Papel & http://ballenablanca.es \\
\hline Politikon & Digital & http://politikon.es \\
\hline La maleta de Port Bou & Papel & http://www.lamaletadeportbou.com \\
\hline El estado mental & Papel & http://www.elestadomental.com \\
\hline \multicolumn{3}{|c|}{ Argentina } \\
\hline Anfibia & Digital & http://www.revistaanfibia.com \\
\hline El puercoespín & Digital & http://www.elpuercoespin.com.ar \\
\hline Orsai & Papel y digital & http://www.orsaibonsai.com \\
\hline Soho & Papel y digital & http://www.soho.com.co \\
\hline Cuarto poder & Papel y digital & http://www.cuartopodersalta.com.ar \\
\hline Chequeando & Digital & http://chequeado.com \\
\hline \multicolumn{3}{|c|}{ Bolivia } \\
\hline Pie izquierdo & Papel y digital & http://www.revistapieizquierdo.com \\
\hline \multicolumn{3}{|c|}{ Colombia } \\
\hline Cronopio & Digital & http://www.revistacronopio.com \\
\hline La silla vacía & Digital & http://www.lasillavacia.com \\
\hline Arcadia & Papel y digital & http://www.revistaarcadia.com \\
\hline El malpensante & Papel y digital & http://www.elmalpensante.com \\
\hline \multicolumn{3}{|c|}{ Chile } \\
\hline The clinic & Digital & http://www.theclinic.cl \\
\hline Ciper Chile & Digital & http://ciperchile.cl \\
\hline \multicolumn{3}{|c|}{ El Salvador } \\
\hline El faro & Digital & http://www.elfaro.net \\
\hline \multicolumn{3}{|c|}{ Guatemala } \\
\hline Plaza pública & Digital & http://www.plazapublica.com.gt \\
\hline \multicolumn{3}{|c|}{ México } \\
\hline Animal político & Digital & http://www.animalpolitico.com \\
\hline Gatopardo & Papel y digital & http://www.gatopardo.com \\
\hline \multicolumn{3}{|c|}{ Perú } \\
\hline Buen salvaje & Papel y digital & http://buensalvaje.com \\
\hline Cometa & Papel y digital & http://cometacomunicacion.com \\
\hline$I D L$ reporteros & Papel y digital & https://idl-reporteros.pe \\
\hline Etiqueta negra & Digital & http://www.etiquetanegra.com.pe \\
\hline \multicolumn{3}{|c|}{ Venezuela } \\
\hline Marcapasos & Digital & http://www.revistamarcapasos.com \\
\hline ProDaVinci & Digital & http://www.prodavinci.com \\
\hline
\end{tabular}


y que no se siente cómodo con la excesiva especialización en áreas de muchas revistas tradicionales. Inspirada en The New Yorker, sus señas de identidad son:

- uso del blanco y negro para facilitar la lectura;

- predominio de la crónica, el reportaje y la entrevista larga;

- cuidada elaboración de los materiales gráficos que acompañan a cada pieza: ilustraciones, fotografías, etc.

Internet ha resultado ser un aliado para la expansión de la revista, dado que su estrategia de divulgación de contenidos y ejemplares impresos se ha concentrado en buena medida en webs y redes sociales (Twitter, Facebook, Menéame, etc.). La alianza con otros medios es otra de las tácticas de expansión. En 2013 crea Soidem, una plataforma de distribución de libros y magazines a la que se han unido recientemente otras publicaciones lentas como Yorokobu, Mongolia o Libero, además de pequeñas editoriales como Varasek, Lupercalia, Gallo Nero, etc. Aunque su redacción no supera en la actualidad la veintena de profesionales, Jot down ha alcanzado prestigio a nivel internacional y cuenta con la firma de reputados periodistas y escritores, como Fernando Savater, Isaac Rosa, Félix de Azúa, Juan Marsé o Enric González.

\section{FronteraD}

\section{http://www.fronterad.com}

Medio online fundado en noviembre de 2009 por el periodista Alfonso Armada. Bajo la cabecera "Un periodismo para las inmensas minorías", la revista se centra en temas relacionados con la cultura, la ciencia y la tecnología, pero los aborda desde un reparto muy singular e innovador de secciones con nombres como:

- Acordeón (dedicada al periodismo de precisión);

- Mientras tanto (para blogs);

- Universo elegante (ciencia y tecnología).

En palabras de su director, la revista se fundó siguiendo la senda de The New Yorker, y dedicando "grandes esfuerzos a investigar y contar de la manera más profunda, ecuánime y amena posible, historias de las que no siempre se habla en el periodismo tradicional, sin preocupación por el espacio pero sí por la verdad"2.

Para sus responsables lo fundamental es proporcionar opciones que satisfagan las necesidades y ambiciones de los lectores, con independencia de las leyes del mercado, y puesto que "se pretendía una revista de información gene-

\section{JOI DOWN}
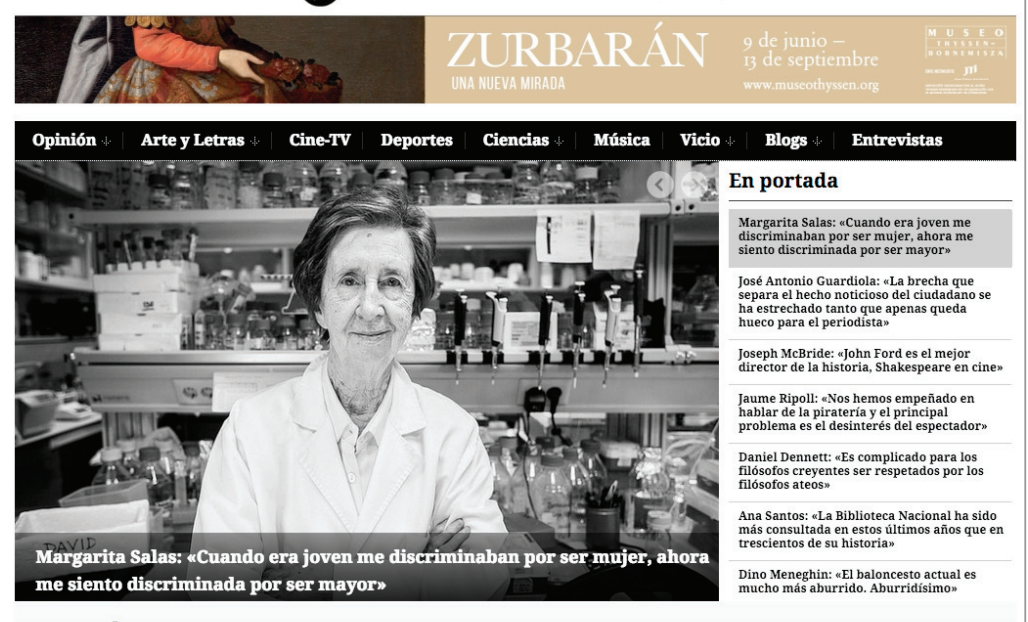

Destacadas
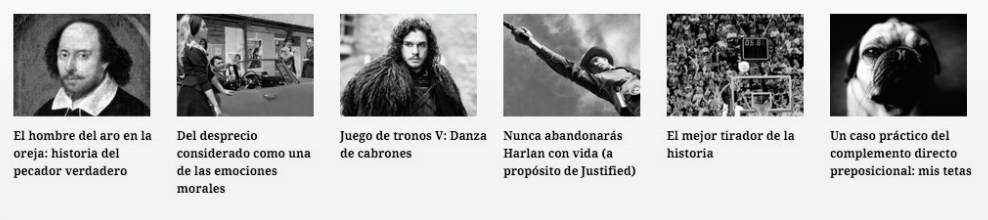

http://www.jotdown.es

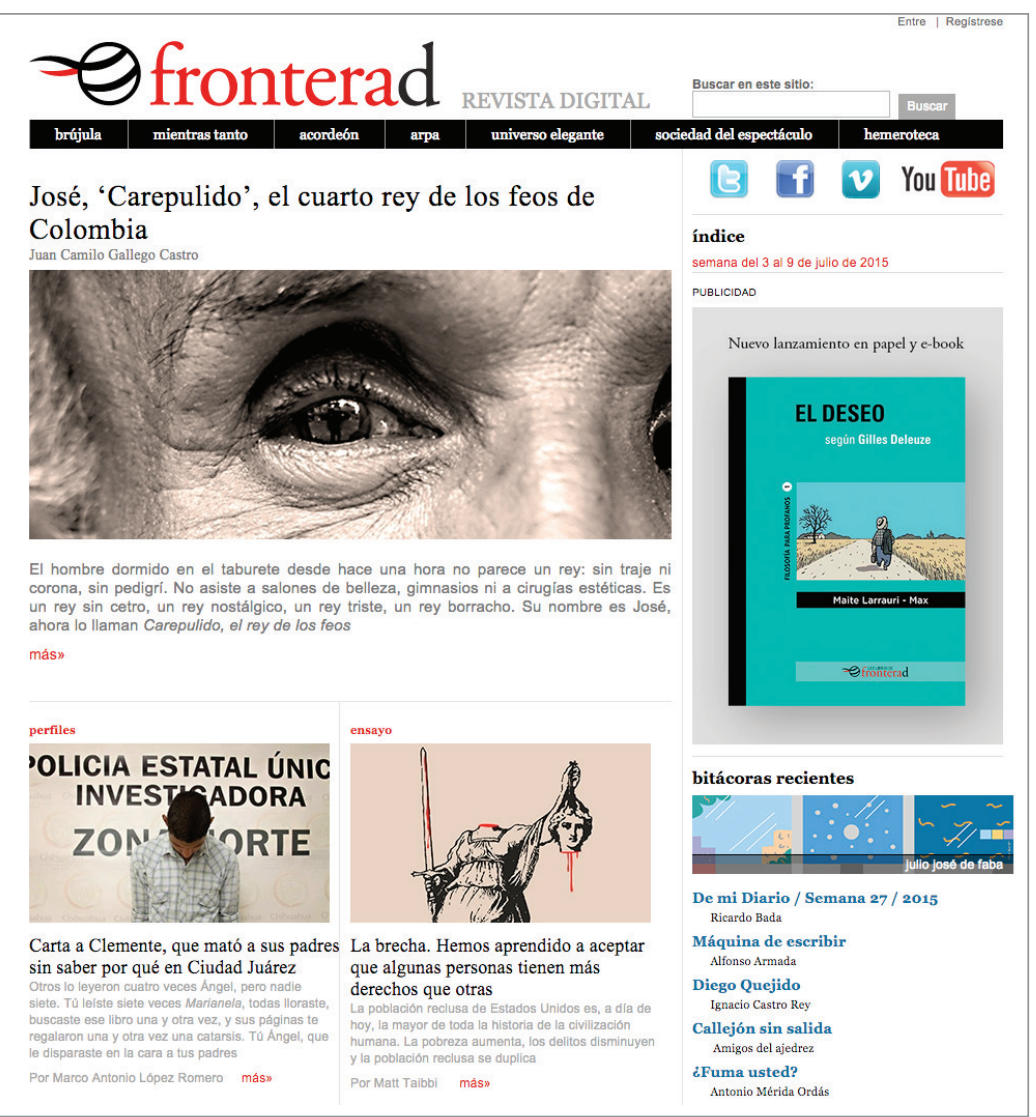

http://www.fronterad.com

ral con temas de largo aliento, cuidadosamente editados y distanciados de la actualidad más cercana porque la realidad no se agota, ni mucho menos, en la actualidad". Sus géneros más característicos son el periodismo narrativo, la crónica, el reportaje y el ensayo; y las largas piezas se suelen complementar con fotografías e ilustraciones muy cuidadas: 
"una de las características de FronteraD es que no existen límites en la extensión de los artículos y reportajes porque se pretende que el periodista tenga toda la libertad para desarrollar sus contenidos y dar a cada tema el espacio que necesite".

\section{La obsesión por la inmediatez provoca un descuido de los valores deontológi- cos clásicos}

En la actualidad solo emplea dos trabajadores, pero cuenta con más de 900 colaboradores. Su modelo de financiación, aún insuficiente, se basa en la publicidad -en especial de fundaciones e instituciones culturales-, que se orienta al mantenimiento de los soportes informáticos. En los últimos meses cuenta también con la publicación de epubs y libros en papel, con cinco títulos editados hasta el momento, entre los que cabe reseñar la Antolojía editada a finales de 2014 que recoge una selección de cerca de 400 páginas de los trabajos publicados a lo largo de los primeros cinco años de la revista.

En 2013 se puso en marcha una iniciativa de crowdfunding para la investigación de Nazaret Castro: Cara y cruz de las multinacionales españolas en América Latina, con la que se recaudaron más de 4.000 euros, de acuerdo a la idea de Armada de que "urge encontrar un modelo que permita pagar decentemente por hacer buen periodismo, y para eso hacen falta lectores dispuestos a apoyarlo".

FronteraD también colaboró en el lanzamiento de la revista FIVE2, subtitulada \#periodismo para lectores sin prisa y editada en diciembre de 2013 por la editorial de Jot down, con más de 200 páginas de artículos de la propia FronteraD, además de Jot down, Alternativas económicas (de Eldiario. es), Periodismo humano y Materia. Estas publicaciones lentas también se embarcaron en la aventura de reeditar en marzo de 2014 un número único del periódico $E /$ heraldo de Madrid, basado en reportajes de actualidad.

http://www.heraldodemadrid.es

\section{La silla vacía \\ http://www.lasillavacia.com}

Revista digital mensual nacida en Colombia en 2009 que centra su atención en la actualidad política del país. Entre otros ideales, su nombre "partió de la idea de que hay un puesto vacío para ser ocupado por un nuevo periodismo y por un nuevo ciudadano"3. Más que prestar cobertura a las noticias del día, las piezas se centran en los personajes e historias que subyacen tras las grandes decisiones políticas de Colombia. La silla vacía es un proyecto creado y dirigido por la periodista Juanita León y nacido con el auspicio del Open Society Institute. En la actualidad se apoya en:

- publicidad tradicional -aunque esta supone menos del $15 \%$ de sus ingresos-;

- impartición de charlas, seminarios y talleres en empresas y universidades;

- aportaciones de los lectores;

- tareas de consultoría en tecnología y cooperación internacional para proyectos específicos.

Su directora considera que el crowdfunding es una vía muy importante de financiación para los medios independientes y que resulta clave para construir una comunidad o club de lectores en torno al proyecto. "Todavía falta mucho para pensar que un medio puede depender sólo de esa de vía de financiación pero en el futuro será probablemente una de las más importantes, puesto que estos medios tienen como única alternativa vivir de sus usuarios"3. Tiene una plantilla de 8 trabajadores, y cuenta con unos 70 colaboradores. Su principal objetivo es revitalizar el periodismo de calidad mediante la promoción de géneros que contribuyen a una amplia contextualización de la realidad política como el reportaje, la entrevista y la crónica. A partir de una original maquetación, fotografías en blanco y negro, y una nutrida base de recursos audiovisuales y multimedia, la revista rescata valores intrínsecos del periodismo como el reporterismo a pie de calle, la pluralidad y el contraste de las fuentes, y la defensa de un periodismo de servicio público que incide en el debate y en la participación de los usuarios, periodistas y líderes de opinión: "Los periodistas debemos mostrar

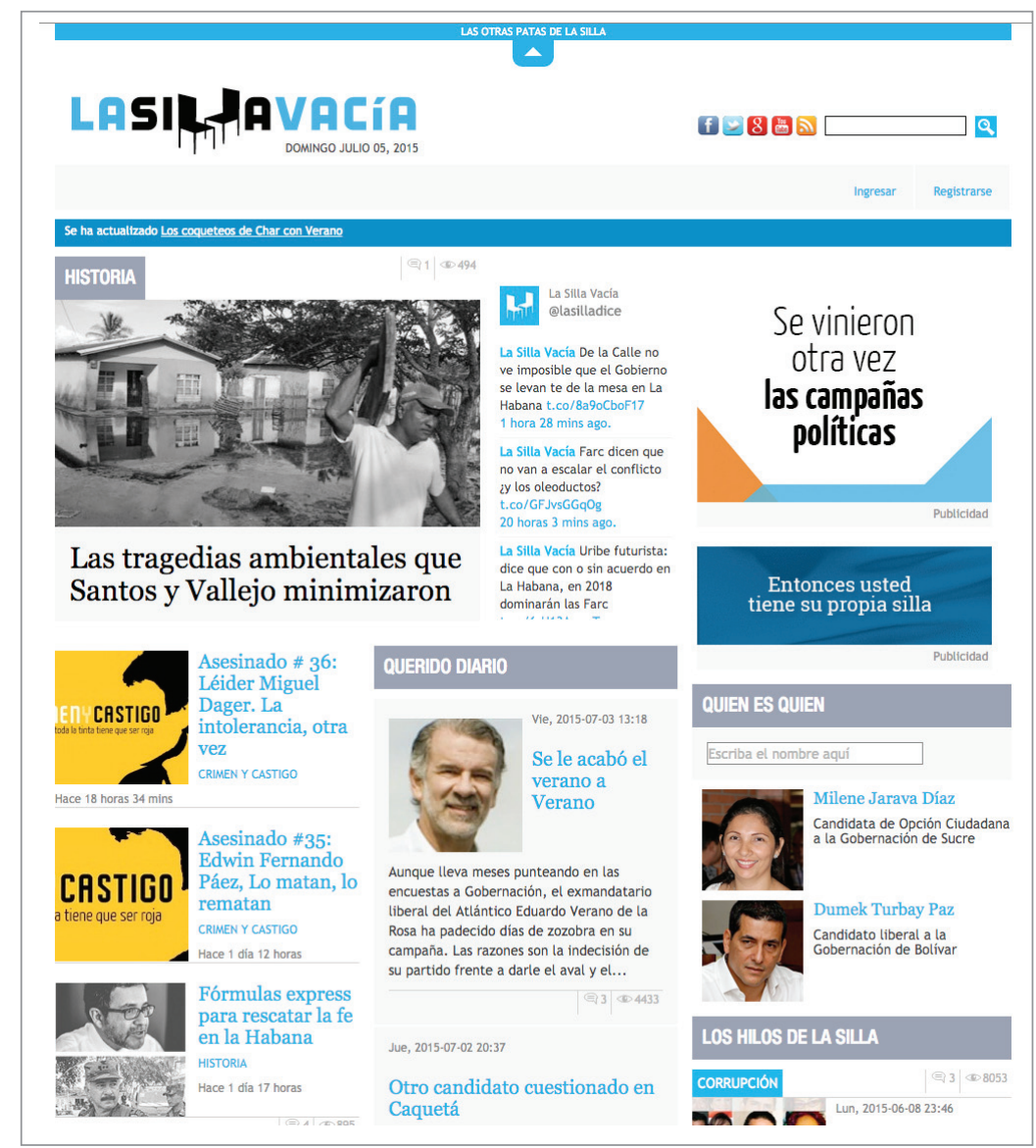

http://www.lasillavacia.com 
no sólo la coyuntura de los hechos, sino su estructura y esa es la misión del periodista: profundizar en los temas y no quedarse sólo con la información superficial”"3.

\section{El puercoespín}

http://www.elpuercoespin.com.ar

Revista digital argentina basada en la narrativa de no ficción y la crónica sobre política, periodismo y cultura, fundada en marzo de 2010 por los periodistas Graciela Mochkofsky y Gabriel Pasquini: "Creíamos que el modo tradicional de hacer las cosas en el periodismo, en todo sentido, se hallaba en crisis, y había que explorar alternativas" (Ávila, 2012). El puercoespín es un sitio web de historias que prioriza la calidad de los relatos sobre las firmas, y que, con talento y perseverancia, ha logrado reunir a un amplio número de colaboradores voluntarios de ámbito internacional, e incluye a renombrados periodistas, intelectuales o fotógrafos. Los informadores pueden crear su propio espacio para potenciar cierto tipo de periodismo narrativo que a muchos medios tradicionales ha dejado de interesar, pero que vuelve a recobrar fuerza en otros casos. De ahí que busquen historias que vayan más allá de la noticia diaria o incluso de la crónica bien escrita, pero efímera o banal: "No nos interesan las noticias instantáneas, sino aquellas que indican tendencias nuevas o cambios o un estado de cosas" (Ávila, 2012). El proyecto fue creado sin ningún capital y se sostiene a partir del trabajo voluntario, las subvenciones públicas y suscripciones a algunos contenidos. Ideado como proyecto digital, no pretende por el momento convertirse o lanzar una publicación impresa.

Los proyectos slow suelen apelar a clubes de lectores especializados

\section{Anfibia}

\section{http://www.revistaanfibia.com}

Revista digital argentina de crónicas y relatos de no ficción dirigida por el periodista y profesor universitario Cristian Alarcón y editada por Federico Bianchini. En opinión de su editor, Anfibia se propone desmalezar algunas zonas de la realidad argentina e internacional con especial énfasis en América Latina, así como ofrecer un viaje literario con el mayor rigor periodístico e investigativo. Su nombre deriva de la idea inicial del proyecto de apostar por las crónicas escritas en tándem entre un cronista y un académico: "Las riendas del relato están en manos del cronista, pero el académico debe proponer ideas sobre cómo abordar el tema, generar nuevas preguntas al cronista, y participar del trabajo de reporteo para lograr, finalmente, una crónica que combine calidad narrativa y una mirada compleja sobre un tema"4. Creada y financiada por la Universidad Nacional de San Martín, y con el apoyo de la Fundación Nuevo Periodismo Iberoamericano, Anfibia se caracteriza por mezclar la mejor narrativa con temas de impacto científico. Según su editor, muchas de las narraciones son crónicas largas, de 20 a 30 mil caracteres, y trabajadas durante uno o varios meses por equipos de cronistas y académicos. La ilustración es un rasgo fundamental de la identidad visual de la revista, puesto que "se buscan formatos de comunicación visual que cuestionen los hechos y los puntos de vista en torno a esos hechos y que no sólo intenten mostrar sino generar pensamiento y reflexionar sobre el status quo imperante en el tratamiento de las noticias y los conflictos". Cuenta con 320 colaboradores entre periodistas, académicos y fotógrafos.

\section{Paralelismos entre los proyectos}

De acuerdo a los ejemplos analizados, cabe afirmar que no existe un modelo cerrado y definitivo de iniciativas periodísticas slow en el ámbito digital español o latinoamericano, puesto que estos y otros medios se caracterizan por una extrema diversidad en objetivos, contenidos, periodicidad o modelos de sostenibilidad. Sin embargo y pese a las diferencias, podemos apreciar una serie de constantes.

Las iniciativas toman su inspiración en el formato de revista o magazín tradicional de carácter impreso, más allá de que ofrecen todos sus contenidos online, habilitando incluso versiones para tabletas y móviles, y, en otros casos, empleando la Red como matriz de contenidos para la edición impresa. 
La estrategia digital es lógica si tomamos en consideración los altos costes que hoy supone editar en papel, además de las posibilidades que ofrece la Red al facilitar una retroalimentación constante por parte de las audiencias, o a fin de contar con un diseño audaz y novedoso que garantice una lectura pausada y sostenida en la que la imagen llega a tener tanta importancia como el propio texto, como es el caso de Anfibia o Jot Down.

En cuanto a su financiación, ninguno de los proyectos forma parte de grandes conglomerados mediáticos, aunque se da una tendencia a establecer sinergias con otros proyectos similares. Por lo general las webs parten de la iniciativa de periodistas o profesionales independientes, que anteponen su línea editorial a la dictada por publicidad o grupos de interés político. Destaca también el recurso a otras fórmulas como la suscripción a números impresos, contenidos online de pago y estrategias de micromecenazgo. Pese a que aspiran a la autosuficiencia económica y a la independencia con respecto a los grandes medios (Domínguez; Pérez-Colomé, 2012), ninguna de las publicaciones presenta hasta el momento directrices claras de sustentabilidad, tal vez por sus escasos años de recorrido (la mayoría nacidas a partir de 2005) y por apoyarse en un negocio digital en extremo sujeto a los vaivenes del mercado: "Los modelos emergentes dan cabida a productos emprendidos por promotores apasionados - periodistas o no- que se rebelan contra la mediocridad en el oficio: rechazan la oferta mayoritaria de los medios de comunicación y apuestan por contenidos que trascienden la inmediatez de la noticia. Sin embargo, admiten carecer de conocimientos empresariales y de marketing avanzados, un hecho que dificulta la rentabilidad de los medios a corto y medio plazo y genera cierta incertidumbre sobre su sostenibilidad a lo largo del tiempo" (Rodríguez-Rodríguez; Albalad-Aiguabella, 2012, p. 306). En cualquier caso, las vías de financiación apuntan a la configuración de "clubes de lectores" especializados que pagan por acceder a ofertas exclusivas, números especiales y asistencia a eventos a cambio de una cuota anual. Esto apoya la idea de que la suscripción no sólo debe orientarse al pago por contenido, sino también a otras actividades como beneficios y descuentos en distintos consumos, preferentemente culturales, para fidelizar a los lectores (CaseroRipollés, 2012).

La capacidad de respuesta de los usuarios y sus conversaciones e interacción con estas publicaciones vía redes sociales (Twitter, Facebook, YouTube, etc.), coadyuvan a la creación de comunidades virtuales que involucran de manera activa a los lectores, lo cual se traduce en promoción del propio medio a través del boca a boca y en su propia fidelización a fin de avanzar hacia un modelo de financiación sostenible. Asimismo las redes sociales les permiten dar a conocer sus proyectos y llegar a su público objetivo sin necesidad de invertir en publicidad tradicional, un coste que por otra parte resultaría inasumible. Internet ha permitido implantar un canal de distribución propio sin apenas intermediarios a la hora de vender los ejemplares impresos (cuando los hay) y se complementa con la venta tradicional de ejemplares en librerías y quioscos especializados.

\section{Las iniciativas toman su inspiración en el formato de revista o magazín tradicional de carácter impreso, aunque ofrecen sus contenidos online}

En cuanto a los contenidos, su configuración en torno a sociedades laborales o limitadas facilita el control de la gestión por parte de los propios trabajadores-socios, y se evita con ello la intromisión de accionistas y anunciantes en su línea editorial, como es el caso de FronteraD o La silla vacía. Esta característica, además de la voluntad expresa de calidad, garantiza una mayor independencia y los configura como espacios con altos niveles de creación y experimentación temática y formal. De ahí que estos medios acaben contando con el apoyo de colaboraciones externas y grandes firmas y no resulte necesario contar con plantillas extensas.

Destaca la presencia de fórmulas de periodismo narrativo y de investigación a partir de dos formatos predominantes, la crónica y el reportaje en profundidad, cuando no cierta 
hibridación de géneros, en todo caso distantes del formato noticia. Son estos los que permiten "humanizar" las informaciones a través del seguimiento de distintas historias de vida, abundante contextualización histórica, o distintas capas expresivas y de fuentes, testimonios y datos. En la declaración de intenciones de los responsables de estos proyectos se reivindica el periodista que sale a la calle para buscar información relevante, se toma su tiempo para encontrar buenas historias, y analiza e interpreta los datos con pausa, en búsqueda de fórmulas atractivas para sus audiencias.

En los medios lentos los profesionales se suelen expresar con suma libertad, adoptando una mirada propia y abordando temas con frecuencia ausentes en la agenda de los grandes medios, pero que tienen relevancia para el lector interesado que, en cualquier caso, no es mayoritario sino un target específico como esas "inmensas minorías" a las que apela FronteraD.

En todos los proyectos se incide en una reivindicación del periodismo de autor, en el que emergen nombres asociados, entre otros, a lo que antes denominamos la "nueva crónica latinoamericana", una generación comparativamente distinta de la de la crónica hegemónica o tradicional y que se interesa por lo cotidiano y las historias mínimas, el testimonio directo de los protagonistas, la implicación del cronista en el propio relato y "la interpelación ética al lector frente a aquello que permanece silenciado y, por ello, invisible" (Callegaro; Lago, 2012, p. 261).

\section{En el futuro la economía del formato lar-} go o corto será lo único que importe en el periodismo

\section{Conclusiones}

En la era del "torrente mediático" (Gitlin, 2005) hay cabida para las iniciativas periodísticas slow si tenemos en cuenta que existen lectores interesados en publicaciones de largo formato y enraizadas en las fórmulas clásicas del periodismo narrativo y de investigación.

Las iniciativas descritas y otras afines que no tuvieron cabida en este estudio, sugieren que existen vías de supervivencia para el periodismo que resultan más complejas pero tal vez más acertadas a largo plazo que las de apelar en exclusiva a un lector ocupado y de atención distraída. Estas sendas recuperan la temporalidad lenta necesaria en cualquier producción periodística de calidad, de acuerdo a un ideal de "sostenibilidad cultural" que para Martín-Barbero (2008) pasa por redimensionar los tiempos "densos" de la cultura frente al cortoplacismo que define a las sociedades modernas. En esta dirección se sitúa también Díaz-Nosty (2013, p. 137) cuando comenta que hoy el periodismo está "sujeto a la alerta permanente, a la observación en tiempo real, pero también a la diferenciación de las velocidades de consumo, a la adecuación de la oferta creciente a la atención de las audiencias".

Tal vez en el futuro la economía del formato largo o corto sea lo único que importe en el periodismo y no tanto el término medio, como sostiene Robert S. Boynton (2011). Es decir, por un lado persistirá el género estrella de la noticia, con formato breve, barato y fácil de producir, máxime con el apoyo de las nuevas tecnologías de la información que están por venir. Pero en el otro extremo, la noticia basada en el registro inmediato y la actualización constante de los hechos convivirá con un periodismo especializado y basado en textos extensos y con una alta factura estética. Este periodismo resulta a todas luces mucho más costoso de producir que el primero. Sin embargo, su oferta segmentada contribuye a la fidelización de las audiencias y es de prever que siga captando la atención de comunidades específicas de lectores ávidos de productos atractivos, de calidad y apegados a sus reclamos, intereses y demandas.

Destaca la presencia de periodismo narrativo y de investigación a partir de dos formatos predominantes: la crónica y el reportaje en profundidad

\section{Notas}

1. Ricardo Jonás en entrevista realizada por Jaurrieta (2014).

2. Periodismo slow. Revista FronteraD. Entrevista realizada por Alejandro Barranquero-Carretero a Alfonso Armada, 11 noviembre 2014.

3. Juanita León en entrevista realizada por Montoya (2013).

4. Periodismo slow. Revista Anfibia. Entrevista realizada por Gloria Rosique-Cedillo a Federico Bianchini, 21 mayo 2014.

\section{Bibliografía}

Andrejevic, Mark (2013). Infoglut: How too much information is changing the way we think and know. London: Routledge. ISBN: 9780415659086

Angulo, María (2013). Crónica y mirada. Aproximaciones al periodismo narrativo. Madrid: Libros del K.O. ISBN: 978 8416001019 http://dx.doi.org/10.7203/KAM.3.3757

Ávila, Sandra (2012). "Revistas en la Red. El puercoespín". Libros, nocturnidad y alevosía, 22 mayo.

http://www.luisbarga.net/2012/05/revistas-en-la-red-iii-elpuercoespin.html

Barranquero-Carretero, Alejandro (2013). "Slow media. Comunicación, cambio social y sostenibilidad en la era del torrente mediático". Palabra clave, v. 16, n. 2, pp. 419-448. http://palabraclave.unisabana.edu.co/index.php/ palabraclave/article/view/3074/3190

Baudrillard, Jean (1984). El sistema de los objetos. México: Siglo XXI. ISBN: 9788432313981

http://monoskop.org/images/1/18/Baudrillard_Jean_El_ sistema_de_los_objetos_1969.pdf

Bauman, Zygmunt (2006). Vida líquida. Barcelona: Paidós. ISBN: 9788449324543

Bourdieu, Pierre (1997). Sobre la televisión. Barcelona: Anagrama. ISBN: 9788433968036 
Boynton, Robert S. (2011). "El nuevo nuevo periodismo: largo, caro y muy bueno, o corto, barato y eficiente". El puercoespín, 14 septiembre.

http://www.elpuercoespin.com.ar

Brabazon, Tara (2013). Digital dieting: From information obesity to intellectual fitness. Farnham: Ashley. ISBN: 978 1472409386

Callegaro, Adriana; Lago, María-Cristina (2012). “La crónica latinoamericana: cruce entre literatura, periodismo y análisis social". Comunicação \& informação, v. 15, n. 1, pp. 46-65. http://dx.doi.org/10.5216/cei.v15i1.22496

Carrión, Jorge (2012). Mejor que ficción. Crónicas ejemplares. Barcelona: Anagrama. ISBN: 9788433925978

Casero-Ripollés, Andreu (2012). "La reconversión del periodismo: Nuevos modelos de negocio en el panorama digital". En: Salgado-García, Fernando; Alejandro-Martínez, Valentín (eds.). Economía de la cultura y de la comunicación en la era digital. Porto: Media XXI, pp. 353-378. ISBN: 978 9897290282

Chung, Debora S.; Yoo, Chan-Yun (2008). "Audience motivations for using interactive features: Distinguishing use of different types of interactivity on an online newspaper". Mass communication \& society, v. 11, n. 4, pp. 375-397. http://dx.doi.org/10.1080/15205430701791048

Craig, Robert T. (1999). "Communication theory as a field". Communication theory, v. 9, n. 2, pp. 116-161. http//dx.doi.org/10.1111/j.1468-2885.1999.tb00355.x

Cushion, Stephen; Lewis, Justin (2010). The rise of 24-hour news television: Global perspectives. New York: Peter Lang. ISBN: 9781433107764

David, Sabria; Blumtritt, Jörg; Köhler, Benedikt (2010). The slow media manifesto.

http://en.slow-media.net/manifesto

Díaz-Nosty, Bernardo (2013). La prensa en el nuevo ecosistema informativo. "iQue paren las rotativas!". La transición al medio continuo. Barcelona y Madrid: Ariel y Fundación Telefónica. ISBN: 9788408112969

http://www.fundaciontelefonica.com/arte_cultura/ publicaciones-listado/pagina-item-publicaciones/?itempubli=238

Domínguez, Eva; Pérez-Colomé, Jordi (2012). Microperiodismos. Aventuras digitales en tiempos de crisis. Barcelona: UOC, ISBN: 9788497884983

Freeman, John (2009a). “Not so fast: Sending and receiving at breakneck speed can make life queasy; a manifesto for slow communication". The Wall Street journal, 29 de agosto. http://www.wsj.com/articles/SB100014240529702035506 04574358643117407778

Freeman, John (2009b). The tyranny of e-mail: The fourthousand-year journey to your inbox. New York: Scribner. ISBN: 9781416576730

Gess, Harold (2012). "Climate change and the possibility of 'slow journalism". Ecquid novi: African journalism studies, v. 33, n. 1, pp. 54-65.

http://dx.doi.org/10.1080/02560054.2011.636828
Gitlin, Todd (2005). Enfermos de información. De cómo el torrente mediático está saturando nuestras vidas. Barcelona: Paidós. ISBN: 8449317134

Greenberg, Susan (2012). "Slow journalism in the digital fast lane". En: Lance, Richard; Tulloch, John (eds.). Global literary journalism: exploring the journalistic imagination. New York: Peter Lang, pp. 381-393. ISBN: 9781433118661

Han, Byung-Chul (2012). La sociedad del cansancio. Barcelona: Herder. ISBN: 9788425428685

Harvey, David (1998). La condición de la postmodernidad. Investigación sobre los orígenes del cambio cultural. Buenos Aires: Amorrortu. ISBN: 9789505186525

http://www.economia.unam.mx/academia/inae/inae2/ u2/2.pdf

Herrscher, Roberto (2012). Periodismo narrativo. Como contar la realidad con las armas de la literatura. Barcelona: Universitat de Barcelona. ISBN: 9788447536382

Honoré, Carl (2012). Elogio de la lentitud. Un movimiento mundial desafía el culto a la velocidad. Barcelona: RBA. ISBN: 9788478715282

Honoré, Carl (2013). La lentitud como método. Cómo ser eficaz y vivir mejor en un mundo veloz. Barcelona: RBA. ISBN: 9788490065327

Jaurrieta, Garbiñe (2014). "Slow journalism" influencing writing practices in startup magazines. A case study research of Jot Down contemporary culture magazine. Trabajo final de grado dirigido por Alejandro Barranquero-Carretero, 13 abril.

Juntunen, Laura (2010). "Explaining the need for speed. Speed and competition as challenges to journalism ethics". En: Cushion, Stephen; Lewis, Justin (Eds.). The rise of 24hour news television: Global perspectives. New York: Peter Lang, pp. 167-182. ISBN: 9781433107764

Koch, Tommaso (2012). "Parrafadas de éxito 'online'”. El país, 30 de agosto.

http://www.cultura.elpais.com/cultura/2012/08/29/ actualidad/1346226060_676549.html

Koselleck, Reinhart (2004). Futures past. On the semantics of historical time. New York: Columbia University. ISBN: 978 0231127714

Le-Masurier, Megan (2015). "What is slow journalism". Journalism practice, v. 9, n. 2, pp. 138-152.

http://dx.doi.org/10.1080/17512786.2014.916471

López-Hidalgo, Antonio; Fernández-Barrero, María-Ángeles (2013). Periodismo de inmersión para desenmascarar la realidad. Salamanca: Comunicación Social. ISBN: 9788415544340

Martín-Barbero, Jesús (2008). Políticas de la comunicación y la cultura: claves de la investigación. Barcelona: Cidob. Serie Dinámicas interculturales.

http://www.portalcomunicacion.com/catunesco/ download/barbero_doc_dinamicas_11.pdf

Maxwell, Richard; Raundalen, Jon; Vestberg, Nina-Lager (2014). Media and the ecological crisis. London: Routledge. ISBN: 9780415709231 
Montoya, María (2013). “Entrevista a Juanita León”. Blog EI cassette, 20 febrero.

Morin, Edgar (2011). La vía para el futuro de la humanidad. Barcelona: Paidós. ISBN: 9788449325939

http://www.edgarmorin.org/descarga-la-via-para-elfuturo-de-la-humanidad.html

Neveu, Erick (2014). "Revisiting narrative journalism as one of the futures of journalism". Journalism practice, v. 15, n. 5, pp. 533-542.

http://dx.doi.org/10.1080/1461670X.2014.885683

Rabhi, Pierre (2013). Hacia la sobriedad feliz. Madrid: Errata Naturae. ISBN: 9788415217435

Ramonet, Ignacio (2011). La explosión del periodismo. De los medios de masas a la masa de medios. Madrid: Clave Intelectual. ISBN: 9788493904708

Rauch, Jennifer (2011). "The origin of slow media: Early diffusion of a cultural innovation through popular and press discourse, 2002-2010". Transformations, n. 20.

http://www.transformationsjournal.org/journal/issue_20/ article_01.shtml

Revers, Matthias (2014). "The twitterization of news making: Transparency and journalistic professionalism". Journal of communication, v. 64, n. 5, pp. 806-826.

http://dx.doi.org/10.1111/jcom.12111

Rocamora, Agnès (2013). "New fashion times: Fashion and digital media". En: Black, Sandy; De-la-Haye, Amy; Entwistle, Joanne; Root, Regina; Thomas, Helen; Rocamora, Agnès (eds.). The handbook of fashion studies. London: Bloomsbury, pp. 61-77. ISBN: 9780857851949

Rodríguez-Rodríguez, Jorge-Miguel; Albalad-Aiguabella, José-María (2012). "Nuevas ventanas del periodismo narrativo en español: del big bang del boom a los modelos editoriales emergentes". Textual \& visual media, n. 5, pp. 287310.

http://www.textualvisualmedia.com/es/archivo/14archivo-de-revistas/36-revista- $n-6$

Rosa, Hartmut (2013). Alienation and acceleration: towards a critical theory of late-modern temporality. New York: Co- lumbia University Press. ISBN: 9788787564144

Rosenberg, Howard; Feldman, Charles S. (2010). No time to think. The menace of media speed and the 24-hour news cycle. New York: Continuum. ISBN: 9780826429315

Rosique-Cedillo, Gloria (2012). “Comunicación e información slow en la era digital: La utopía posible". En: VictoriaMas, Juan-Salvador; Gómez-Tinoco, Alicia; Arjona-Martín, José-Borja (coords.). Comunicación slow (y la publicidad como excusa). Madrid: Fragua, pp. 315-342. ISBN: 97884 70745195

Saltzis, Kostas (2012). "Breaking news online. How news stories are updated and maintained around-the-clock". Journalism practice, v. 6, n. 5-6, pp. 702-710.

https://goo.gl/GUU47I

http://dx.doi.org/10.1080/17512786.2012.667274

Serrano-Puche, Javier (2014). "Hacia una 'comunicación slow': el hábito de la desconexión digital periódica como elemento de alfabetización mediática". Trípodos, v. 1, n. 34, pp. 201-214.

http://www.tripodos.com/index.php/Facultat_ Comunicacio_Blanquerna/article/view/172/77

Sieberg, Daniel (2011). Digital diet: The 4-step plan to break your tech addiction and regain balance in your life. New York: Three River Press. ISBN: 9780307887382

Spence, Edward H.; Quinn, Aaron (2008). "Information ethics as a guide for new media". Journal of mass media ethics, v. 23, n. 4 , pp. 264-279.

http://dx.doi.org/10.1080/08900520802490889

Virilio, Paul (2012). La administración del miedo. Madrid: Barataria. ISBN: 9788492979257

Williams, Eric (2011). "Environmental effects of information and communications technologies". Nature, n. 479, pp. 354358.

http://www.nature.com/nature/journal/v479/n7373/full/ nature10682.html

http://dx.doi.org/10.1038/nature10682

Whitworth, Andrew (2009). Information obesity. Oxford: Chandos Publishing. ISBN 9781843344490

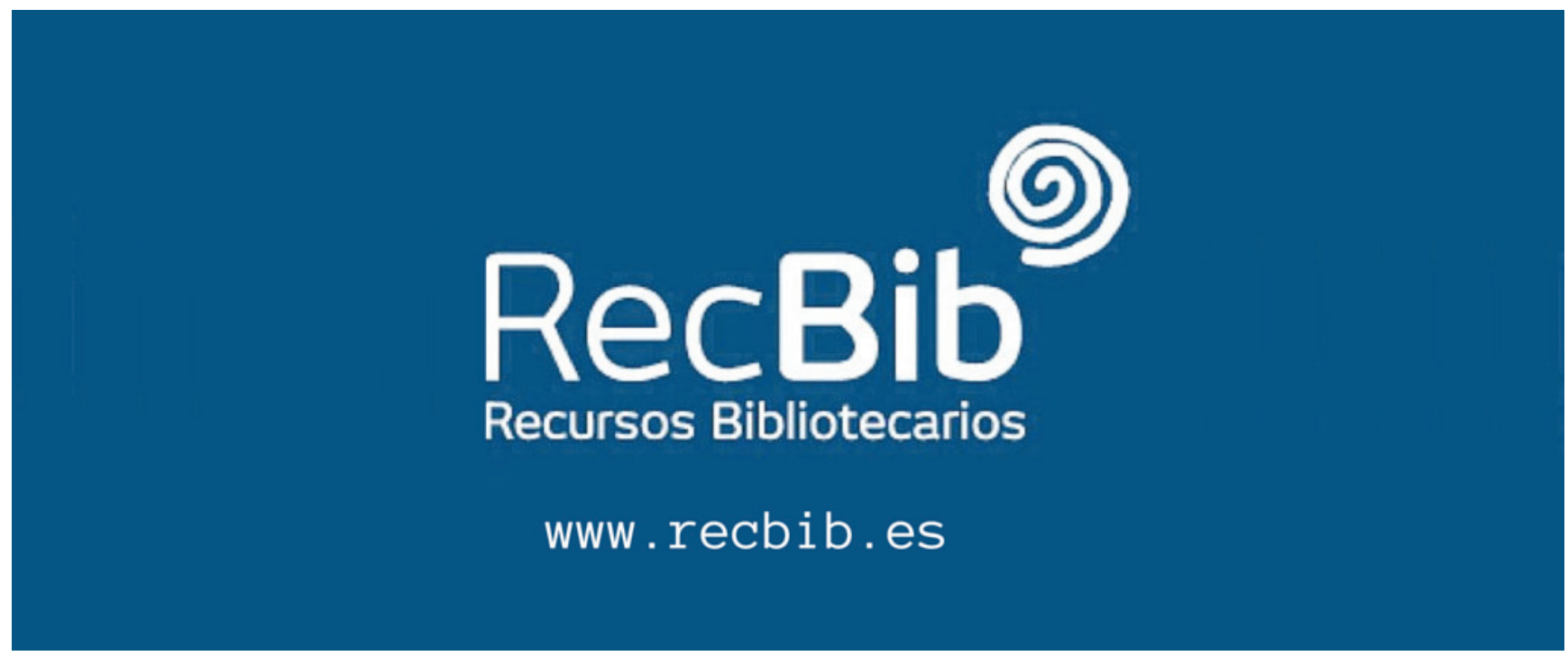

